\title{
Exploring the Social Impacts of the COVID-19 Pandemic on People Living with HIV (PLHIV): A Scoping Review
}

\author{
Jordan J. Winwood ${ }^{1}$ (I) $\cdot$ Lisa Fitzgerald ${ }^{1} \cdot$ Bernard Gardiner $^{1} \cdot$ Kate Hannan $^{1} \cdot$ Chris Howard $^{2} \cdot$ Allyson Mutch $^{1}$
}

Accepted: 6 May 2021 / Published online: 21 May 2021

(c) The Author(s), under exclusive licence to Springer Science+Business Media, LLC, part of Springer Nature 2021

\begin{abstract}
Understanding the clinical impact of COVID-19 has been central to emerging research in the HIV field, but in focusing on the biomedical, researchers must not overlook the socially embedded nature of HIV and the potential social impacts of this new pandemic on PLHIV. We conducted a scoping review to explore emerging research examining the social impacts of COVID-19 on PLHIV in OECD countries over the first 12 months of the pandemic. Twenty articles were identified and included for review. Key themes included: impacts on HIV care access/telehealth; stress and mental health; social isolation and loneliness; food insecurity; changes to sexual behaviour; changes to substance use; impacts on income, education and employment; and racial and social inequality. Results from this review can help guide research into areas where it is needed to help minimise the negative social impacts of the COVID-19 pandemic.
\end{abstract}

Keywords HIV $\cdot$ PLHIV $\cdot$ COVID-19 $\cdot$ Coronavirus $\cdot$ Social impact

\section{Introduction}

COVID-19, caused by SARS-COV-2 coronavirus, has spread to 219 countries and territories, with the death toll surpassing 2.7 million in March 2021 (Mar 20) [1]. Globally, many governments have implemented public health containment measures, which in some countries have included mandatory stay at home orders, physical distancing and mask wearing, with more extensive measures for those considered most vulnerable to infection [2]. Although necessary to relieve pressure on healthcare systems, many of those required to quarantine and self-isolate face uncertain economic and psychosocial outcomes [2].

Evidence investigating whether people living with HIV (PLHIV) are at heightened risk of COVID-19 complications and mortality remains mixed, particularly for those with co-morbid conditions e.g., [3-9]. Some suggest effective antiretroviral treatment (ART) may prevent poorer COVID-19 outcomes [10], but again the evidence base is

Jordan J. Winwood

j.winwood@uqconnect.edu.au

1 School of Public Health, University of Queensland, 288 Herston Road, Brisbane, QLD 4006, Australia

2 Queensland Positive People (QPP), 21 Manilla St, East Brisbane, QLD 4169, Australia inconclusive [7, 11]. So, while the biomedical impacts of COVID-19 on PLHIV are the subject of ongoing investigation, we must not forget the socially embedded nature of HIV $[12,13]$, and the need to also understand the social impact of the current pandemic on PLHIV.

HIV and COVID-19 share many social parallels, including increased stress and anxiety associated with contracting or transmitting the disease [2]. Stress and poor mental health outcomes may be amplified through reignited trauma experienced during the early years of the HIV pandemic, along with contemporary stress linked to increased rates of unemployment and loss of income in the pandemic led downturn [2]. Many PLHIV already face social exclusion due to enacted or perceived HIV-stigma, or socially disconnect as a coping mechanism, which may again impact access to HIV care $[14,15]$. In sum, researchers have raised concerns that many PLHIV are at heightened risk of COVID-19 complications as they try to navigate the physical and social isolation, stigma and discrimination, and/or social and financial precarity that challenges their ability to maintain HIV treatment protocols and quality of life [2, 16, 17]. This review systematically examines these concerns and investigates how the HIV research community has sought to understand and respond to the (social) impacts of COVID-19 on PLHIV. Understanding the early impacts of COVID-19 provides a critical reference point from which health care professionals, 
policy makers, and service providers can respond and provide vital support to PLHIV.

\section{Methods}

This systematically conducted review explored research investigating the impact of COVID-19 on PLHIV as the pandemic emerged. To provide a broad overview of contemporary research investigating COVID-19 and HIV during the first 12 months of the pandemic, we conducted the review in two phases: (1) a global mapping of the literature examining COVID-19 and HIV; and (2) an in-depth examination of literature exploring the social impacts of COVID-19 on PLHIV. Given the diverse global response to the COVID-19 pandemic, phase two of the review focused on high income (OECD) countries that had comparable healthcare and social landscapes and where new research was most rapidly developing (see Table 1). This study involved a search of the literature published in the first 12 months of the pandemic, between January 1, 2020 and January 31, 2021. Electronic searches were conducted using key databases-PubMed, Embase, CINAHL, Web of Science and Scopus. Using keywords, their synonyms and $\mathrm{MeSH}$ terms, a combination of search words were used with Boolean operators "OR" and "AND" (see Table 2). Hand searches of the top 20 AIDs and HIV journals, based on the Google Scholar five-year citation index, were also conducted to maximise the scope of the review and identify additional articles using the list of COVID-19 search terms (see Table 3).

3792 articles were identified through databases and a further 86 through direct journal searches (Fig. 1). After removing duplicates, the title and abstracts of the remaining 1914 articles were screened. Articles were excluded if they were not published in English (or with a full English translation) and/or were published before 2020. Screening by title and abstract excluded 1497 articles that were not directly related to HIV and COVID-19 (e.g., articles that did not explicitly report on an association between HIV and COVID-19, or only briefly mentioned HIV as part of a discussion of other infectious diseases such as tuberculosis). This process was verified by two reviewers at both phases of the process. The remaining 417 articles were categorised
Table 1 Characteristics of studies

Table 2 Search terms used for databases

\begin{tabular}{llll}
\hline Editorials* & & $\mathrm{n}=262 / 417(62.8 \%)$ & \\
\hline Original Research & & $\mathrm{n}=155 / 417(37.2 \%)$ & $\mathrm{n}=155$ \\
Type of study & $\mathrm{n}=155$ & Outcome domain & $108(69.7 \%)$ \\
Case study/series & $62(40.0 \%)$ & Biomedical & $10(6.5 \%)$ \\
Cross-sectional survey & $31(20.0 \%)$ & Sexual behaviours & $16(10.3 \%)$ \\
Cohort study & $24(15.5 \%)$ & HIV care access and telehealth & $7(4.5 \%)$ \\
Qualitative study (e.g. interview) & $12(7.7 \%)$ & Stress and mental health & $2(1.3 \%)$ \\
RCT & $13(8.4 \%)$ & Substance use & $12(7.7 \%)$ \\
Data analysis/modelling & $13(8.4 \%)$ & Other*** & $\mathrm{n}=155$ \\
Study location & $\mathrm{n}=155$ & Population & $117(75.5 \%)$ \\
USA & $42(27.1 \%)$ & PLHIV & $14(9.0 \%)$ \\
Australia & $3(1.9 \%)$ & MSM & $4(2.6 \%)$ \\
China & $21(13.6 \%)$ & Young PLHIV & $3(1.9 \%)$ \\
Economically developed country** & $41(26.5 \%)$ & Transgender PLHIV & $2(1.3 \%)$ \\
Economically developing country** & $42(27.1 \%)$ & PLHIV with substance dependence & $15(9.7 \%)$ \\
Global/ multinational & $6(3.8 \%)$ & Other (including sex workers) & \\
\hline
\end{tabular}

*Includes editorials, letters to editor, commentaries, viewpoints and reviews

**OECD definitions were applied

***Includes economic impacts, racial and social inequality and stigma

\begin{tabular}{ll}
\hline HIV/AIDS & COVID-19 \\
\hline HIV & Coronavirus \\
AIDS & "Coronavirus disease 2019" \\
"Human immunodeficiency virus" & COVID-19 \\
"Acquired immune deficiency syndrome" & SARS \\
"Acquired immunodeficiency syndrome" & SARS-COV-2 \\
PLHIV OR "people living with HIV" & "Severe acute respiratory syndrome"
\end{tabular}


Table 3 The 20 journals included for hand search

Publication

1. Journal of Acquired Immune Deficiency Syndromes

2. AIDS

3. The Lancet HIV

4. AIDS and Behaviour

5. Journal of the International AIDS Society

6. Current opinion in HIV and AIDS

7. Current HIV/AIDS Reports

8. Retrovirology

9. AIDS Care

10. HIV Medicine

11. AIDS Patient Care and STDs
12. International Journal of STD \& AIDS

13. AIDS Research and Human Retroviruses

14. Antiviral Therapy

15. Journal of Virus Eradication

16. Journal of the Association of Nurses in AIDS Care

17. AIDS Research and Therapy

18. AIDS education and prevention

19. HIV/AIDS: Research and Palliative Care

20. Journal of the International Association of Providers of AIDS Care (JIAPAC)
Fig. 1 PRISMA diagram of article screening for inclusion and analysis in this review

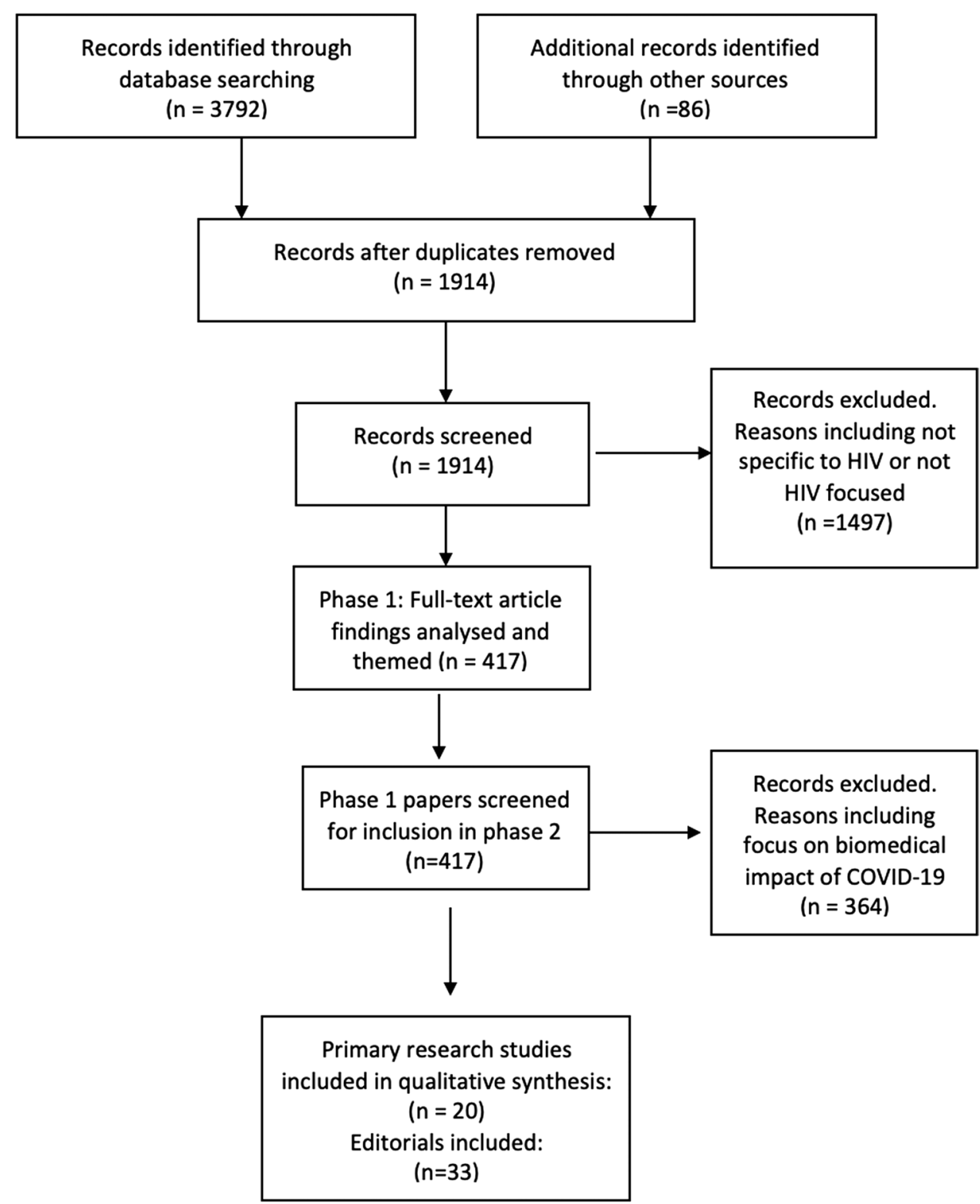


into publication location, outcome domain, type of study and population (see Table 1).

The second phase of the review explored the social impacts of the COVID-19 pandemic on PLHIV. To investigate, a set of inclusion criteria were used to identify articles that directly related to the social consequences of COVID-19 on PLHIV. An article was included if it: involved primary research conducted in an OECD country; and examined the social impacts of COVID-19 on PLHIV. Studies were also included if they explicitly identified and described results for a sub-sample of PLHIV participants. Due to the contemporary nature of the pandemic, preprints and accepted manuscripts were included. In line with the focus of the research, editorials and commentaries were also included as they provided important signposts for critical topics and points of concern within the HIV research and clinical community. Articles were excluded if the main research focus or outcome related to the biomedical or clinical impacts of COVID-19.

\section{Analysis}

The titles and abstracts of studies included in the second phase were examined and separated into editorials and primary research. Drawing on Braun and Clarke's (2006) processes of thematic analysis, editorials were summarised and content themed [18]. Key data (e.g., sample characteristics, study design, findings, outcome measures) were also extracted from the primary research articles and findings coded and themed (see Table 4).

\section{Results}

\section{Phase 1: Summary of Research from the First Twelve Months of the Pandemic}

To consider how the HIV research community has responded to the first twelve months of the pandemic, Table 1 details the characteristics of the 417 articles identified in phase one that examined global research investigating the association between COVID-19 and HIV. Although articles could potentially present findings on more than one outcome or population, for clarity articles are themed by the most predominant focus. Not surprisingly, the main focus of the research $(69.7 \%: 108)$ was the clinical impacts of COVID-19 on PLHIV. This early research provided important insight into the biomedical impact of COVID-19, but the need for more robust, high quality evidence was also clearly evident. The USA was the primary location of research $(27.1 \%: 42)$ and combined with other developed countries made up more than half of all studies. Nearly two-thirds (62.8\%:262) of the publications were editorials, commentaries and reviews. Of the remaining 155 primary research articles, the majority were individual case studies $(40.0 \%: 62)$ followed by cross sectional (20.0\%:31) and cohort studies (15.5\%:24). A handful of studies involved qualitative research (7.7\%:12). Most studies were concerned with the broader population of PLHIV or men who have sex with men (MSM), while nine studies focused on particular sub-populations including transgender PLHIV, PLHIV and substance use, and PLHIV within younger or older age demographics.

\section{Summary of Social Impact Studies}

For phase two, inclusion criteria were applied to the 417 articles to isolate primary research investigating the social impacts of COVID-19 on PLHIV. Twenty primary research studies and 33 editorials/commentaries were identified. Sixteen studies were conducted within three countries: the USA, Australia and Turkey, one study was conducted across Belgium and Brazil and the final three studies were conducted across multiple nations [19-22] (see Table 4 for included countries). Sixteen studies were quantitative, with an additional survey involving open-ended questions, two involved semi-structured qualitative interviews and one detailed a case series (see Table 4).

The research investigated a range of topics including, mental health and stress [20,21, 23, 24], access to health care [22, 25], experiences of stigma [26], factors impacting medication adherence [27] and social precarity [28]. One US study involved a case series of PLHIV who had been diagnosed with COVID-19 [9] and three studies focused on unique subgroups of PLHIV, including African American and Latinx PLHIV [29], PLHIV with substance use disorders [30] and transgender women living with and without HIV [28].

Participant recruitment and data collection is a time intensive task, but many studies drew on internet-based surveys or worked with existing cohorts to gather early information on the impact of COVID-19. For example, four studies involved cross sectional surveys conducted online or via social networking apps Grindr and Hornet [19, 22, 31, 32]. One study involved semi-structured qualitative interviews with 15 racially diverse PLHIV who had been part of an HIV care intervention [29]. A number of studies involved existing cohorts, including a sample of transgender women living with HIV [28], an Australian cohort of gay men and MSM who were recruited in 2014 [33], and two studies involved surveys of older PLHIV who were participants of previous studies [24, 34]. One study involved a wellbeing trial, cancelled due to COVID-19, that engaged participants in a survey to measure the impacts of the new pandemic on their mental health and HIV care outcomes [24]. Another study 


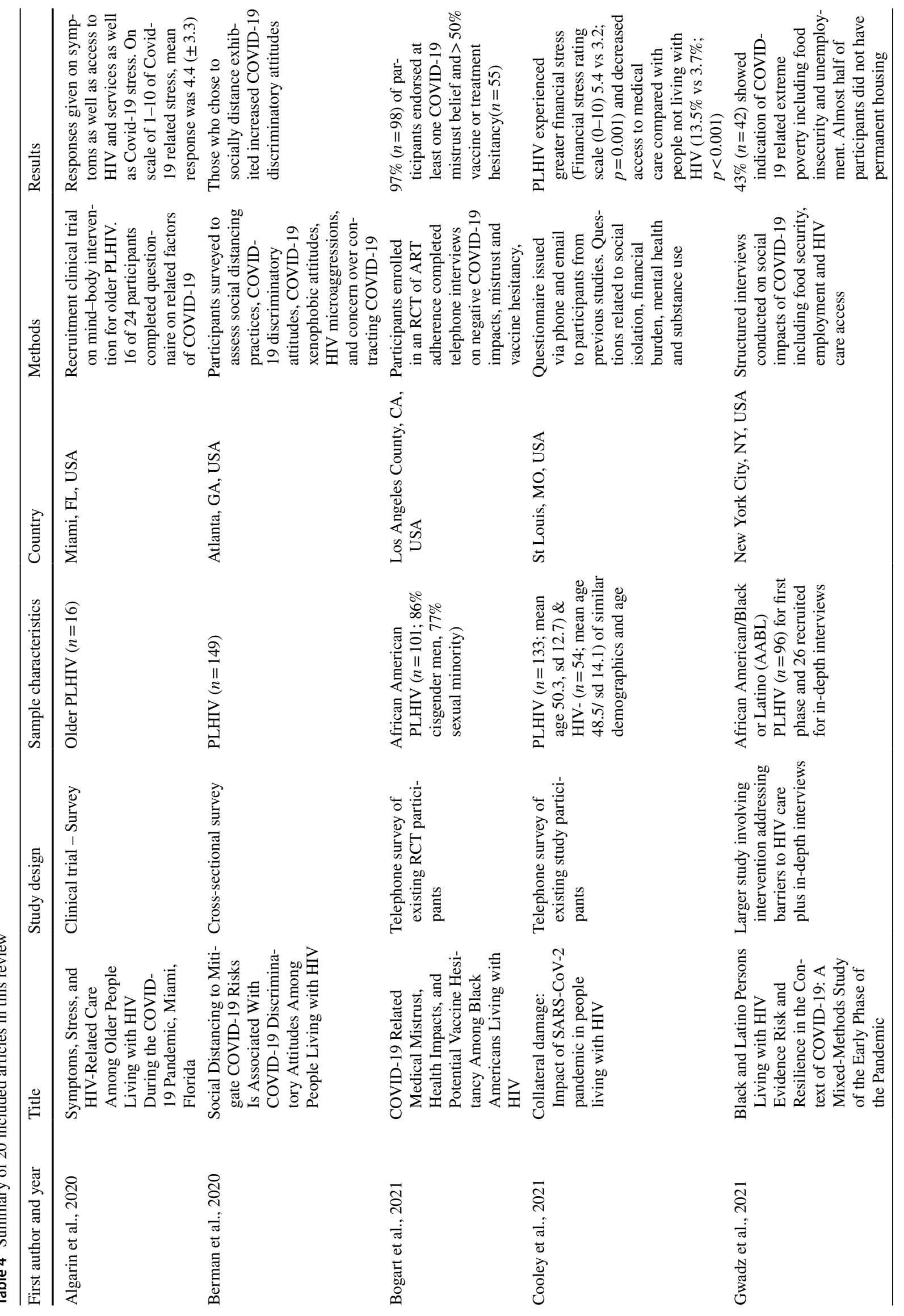




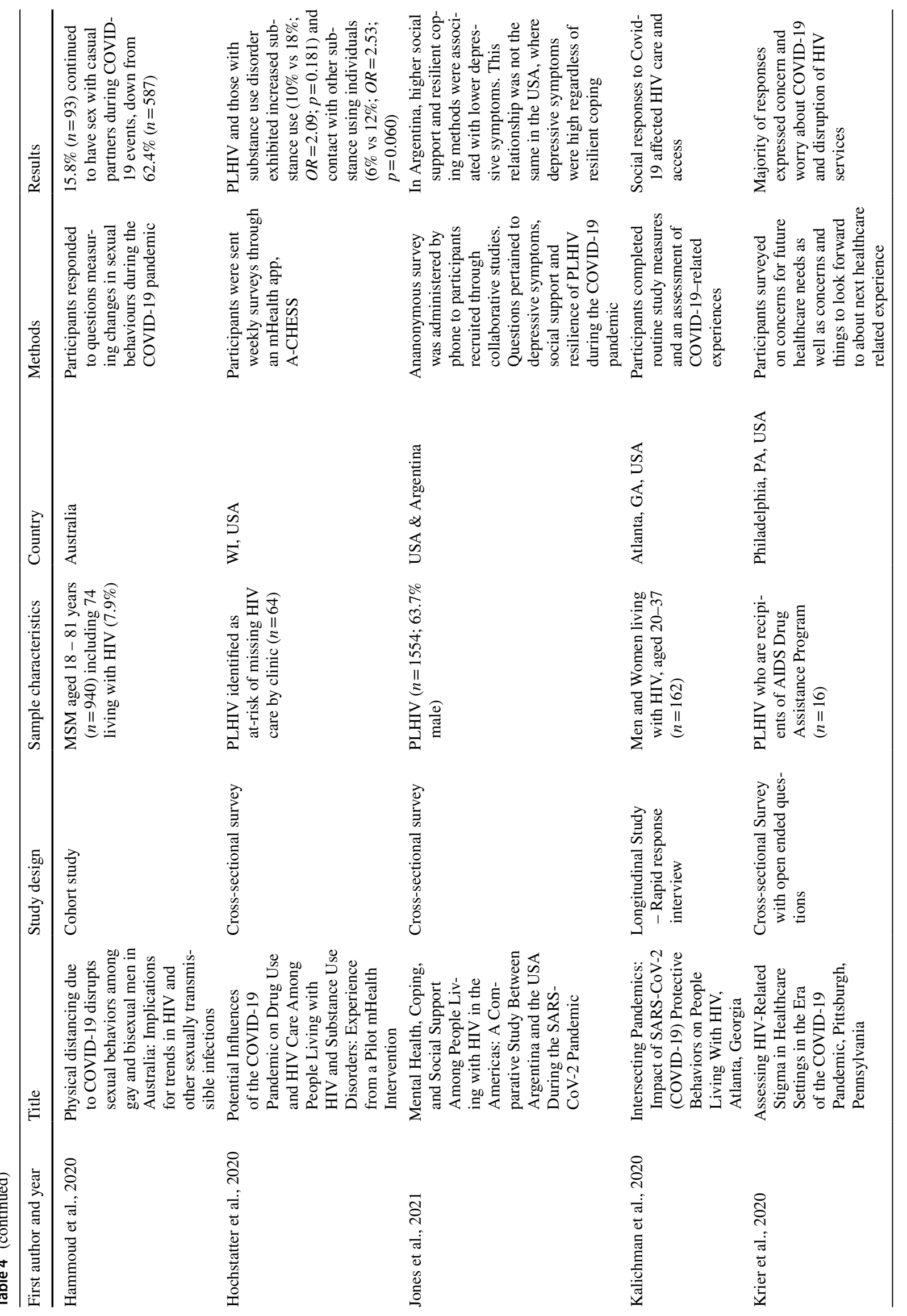




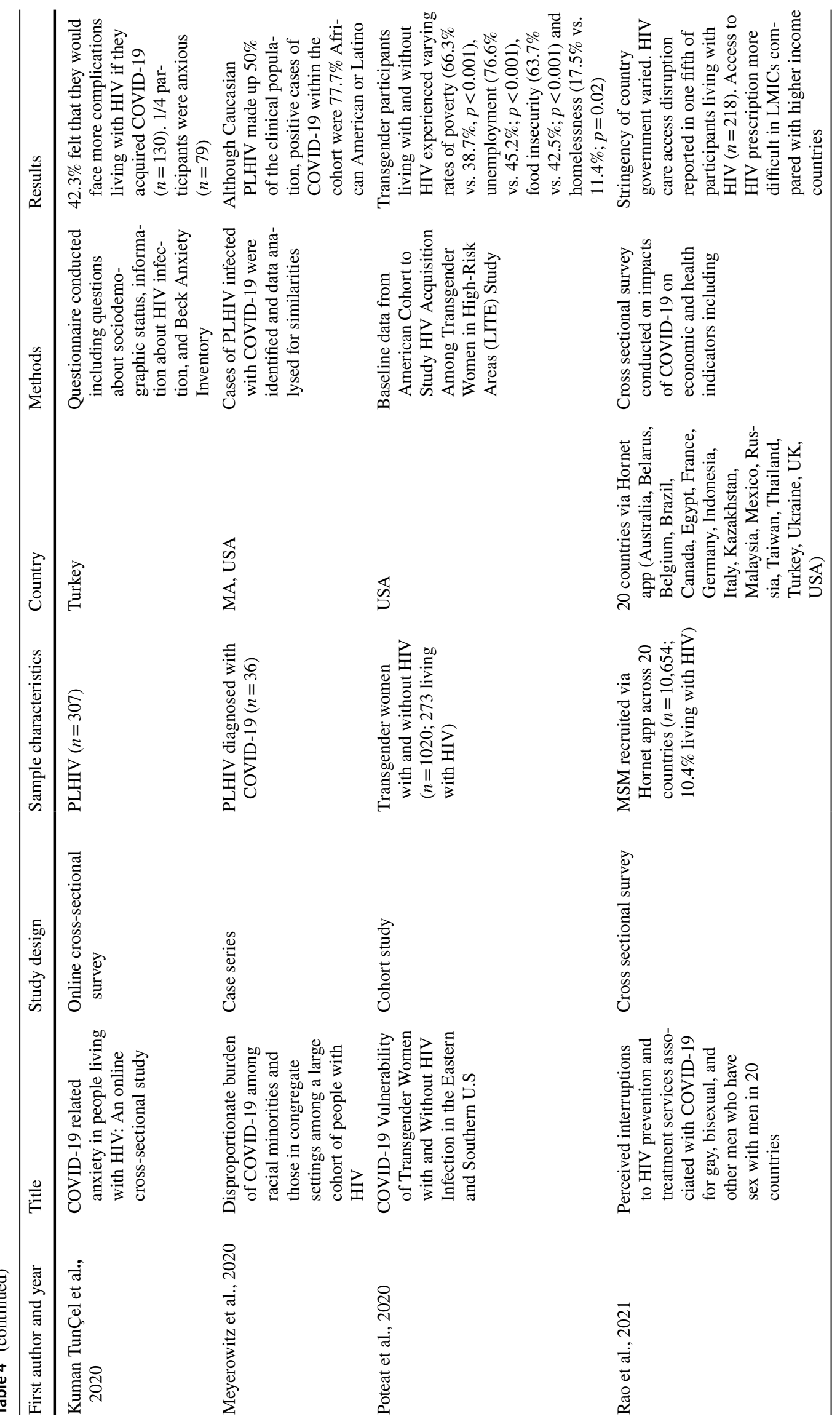




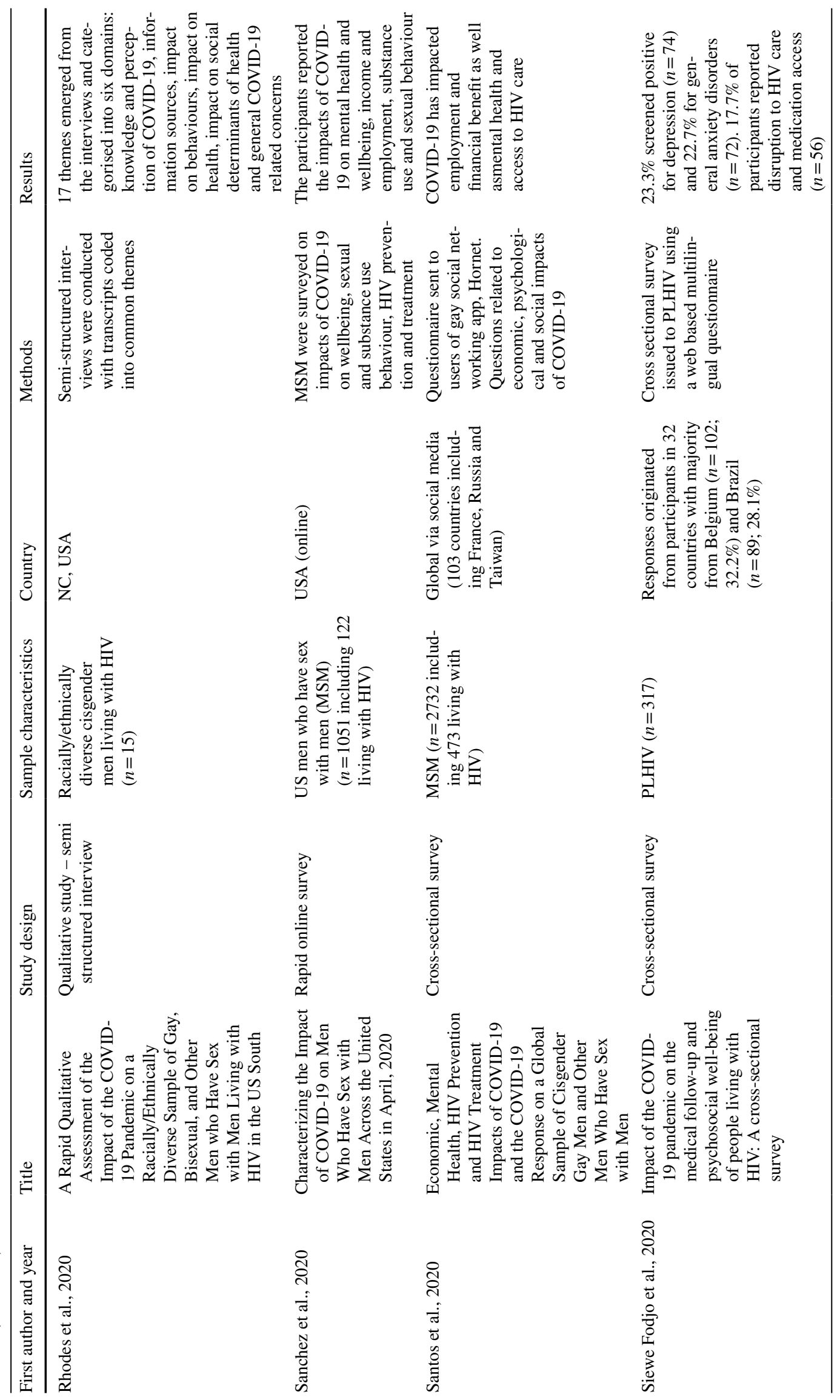




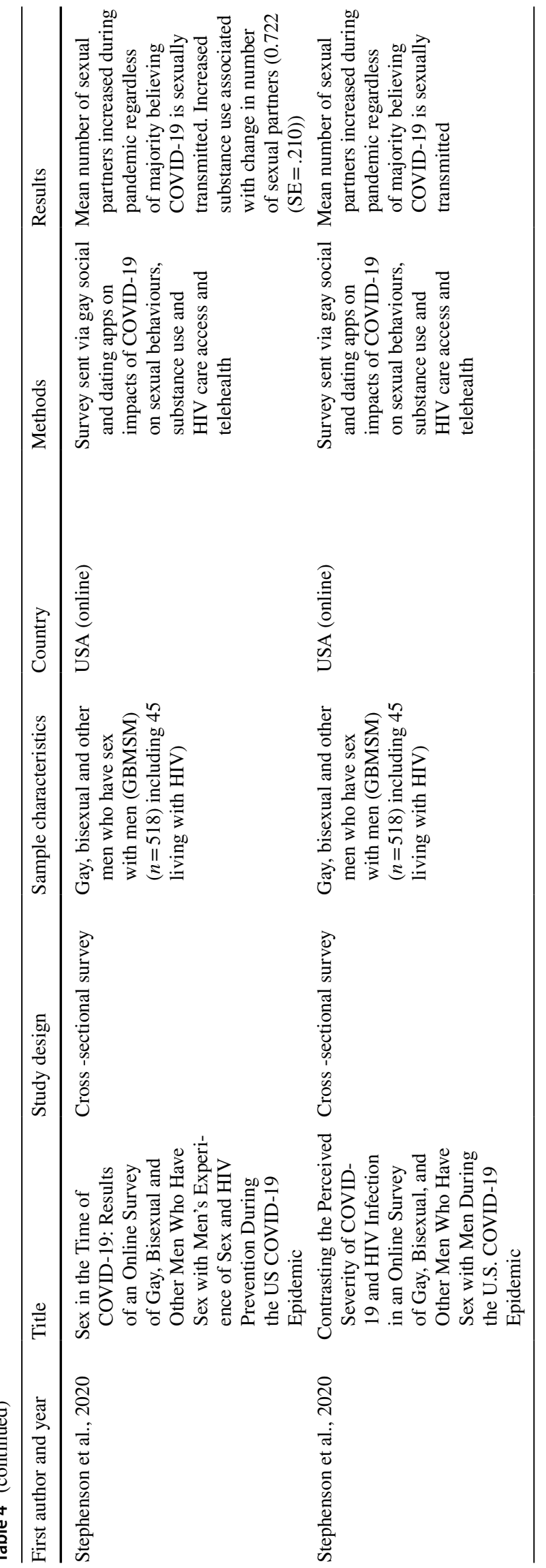

involved a survey of existing participants of a randomised controlled trial involving antiretroviral therapy (ART) adherence [35]. Of the twenty studies, only twelve used samples of participants consisting entirely of PLHIV. Five studies focused on MSM as a cohort and included subsamples of men living with HIV (range 7.9-17.0\% of participants) [19, $22,31-33,36]$. The results of one study are reported across two articles $[32,36]$.

\section{Trends in the Literature}

Eight key themes relating to the social impact of COVID-19 on PLHIV were identified across the 20 primary research studies: HIV care disruption and telehealth, stress and mental health, food insecurity, social isolation and loneliness, impacts on income, education and employment, impacts on sexual behaviours, impacts on substance use, and racial and social inequality and stigma (Table 5). Thematic analysis of the 33 editorials highlighted similar themes including, stigma, mental health, stress, and growing inequalities linked to COVID-19, particularly across racial groups.

\section{Telehealth and Disruption of HIV Care}

Disruption to HIV care and the shift to telehealth was highlighted by more than half the editorials and primary research studies. Telehealth, or telemedicine, has been rapidly implemented to minimise face-to-face contact and allow clinics to maintain care during the pandemic [37, 38, 39]. A number of editorials noted that while telemedicine was necessary during the COVID-19 crisis, they argued it must be customised for PLHIV with poor access to technology or low levels of technological literacy [40, 41]. Beima-Sofie et al. [42] also suggested the relationship between care providers and PLHIV must be carefully managed to reduce long term health impacts and existing health disparities, while Brown \& Weissman [43] raised concerns about the pandemic's impact on ART adherence and retention in care. Operario and colleagues [44] argued not-for-profit organisations are experiencing budget cuts and closure of face-to-face facilities, which further reduces social support for PLHIV.

Within the primary research, disruption of HIV care and the transition to telehealth was the most commonly reported impact of the pandemic [19, 20, 22, 24, 25, 27, 29-32, 34-36, 45]. Santos and colleagues [19] found nearly one in four participants $(23.0 \%)$ in their global survey had lost access to their regular HIV healthcare providers, while Siewe-Fodjo and colleagues [20] found that around $8.0 \%$ of their participants from Brazil and Belgium reported difficulties obtaining antiretroviral medication during the pandemic. Missed appointments were reported by both participants and healthcare providers [27, 31], with two studies reporting that nearly half their participants had 
Table 5 Themes identified across the 20 primary research articles

\begin{tabular}{|c|c|c|c|c|c|c|c|c|}
\hline & $\begin{array}{l}\text { HIV care } \\
\text { and tel- } \\
\text { ehealth }\end{array}$ & $\begin{array}{l}\text { Stress \& } \\
\text { mental } \\
\text { health }\end{array}$ & Food insecurity & $\begin{array}{l}\text { Social isola- } \\
\text { tion \& loneli- } \\
\text { ness }\end{array}$ & $\begin{array}{l}\text { Impacts on } \\
\text { income, educa- } \\
\text { tion \& employ- } \\
\text { ment }\end{array}$ & $\begin{array}{l}\text { Impacts on } \\
\text { sexual behav- } \\
\text { iours }\end{array}$ & $\begin{array}{l}\text { Impacts on } \\
\text { substance } \\
\text { use }\end{array}$ & $\begin{array}{l}\text { Racial \& social } \\
\text { inequality, } \\
\text { stigma }\end{array}$ \\
\hline $\begin{array}{l}\text { Algarin et al., } \\
2020\end{array}$ & $\sqrt{ }$ & $\sqrt{ }$ & & $\sqrt{ }$ & & & & \\
\hline $\begin{array}{l}\text { Berman et al., } \\
2020\end{array}$ & & & & $\sqrt{ }$ & & & & $\sqrt{ }$ \\
\hline $\begin{array}{l}\text { Bogart et al., } \\
2021\end{array}$ & $\sqrt{ }$ & & & & $\sqrt{ }$ & & & $\sqrt{ }$ \\
\hline $\begin{array}{c}\text { Cooley et al., } \\
2021\end{array}$ & $\sqrt{ }$ & $\sqrt{ }$ & $\sqrt{ }$ & $\sqrt{ }$ & $\sqrt{ }$ & & $\sqrt{ }$ & \\
\hline $\begin{array}{c}\text { Gwadz et al., } \\
2021\end{array}$ & $\sqrt{ }$ & $\sqrt{ }$ & $\sqrt{ }$ & & $\sqrt{ }$ & & & $\sqrt{ }$ \\
\hline $\begin{array}{l}\text { Hammoud } \\
\text { et al., } 2020\end{array}$ & & & & & & $\sqrt{ }$ & & \\
\hline $\begin{array}{l}\text { Hochstatter } \\
\text { et al., } 2020\end{array}$ & $\sqrt{ }$ & & & & & & $\sqrt{ }$ & \\
\hline $\begin{array}{l}\text { Jones et al., } \\
2021\end{array}$ & & $\sqrt{ }$ & & & $\sqrt{ }$ & & & \\
\hline $\begin{array}{l}\text { Kalichman } \\
\text { et al., } 2020\end{array}$ & $\sqrt{ }$ & & $\sqrt{ }$ & $\sqrt{ }$ & & & & \\
\hline $\begin{array}{l}\text { Krier et al., } \\
2020\end{array}$ & $\sqrt{ }$ & $\sqrt{ }$ & & & & & & \\
\hline $\begin{array}{l}\text { Kuman TunÇel } \\
\text { et al., } 2020\end{array}$ & & $\sqrt{ }$ & & & & & & \\
\hline $\begin{array}{l}\text { Meyerowitz } \\
\text { et al., } 2020\end{array}$ & & & & & & & & $\sqrt{ }$ \\
\hline $\begin{array}{l}\text { Poteat et al., } \\
2020\end{array}$ & & & $\sqrt{ }$ & & $\sqrt{ }$ & & & $\sqrt{ }$ \\
\hline Rao et al., 2021 & $\sqrt{ }$ & & & & & & & \\
\hline $\begin{array}{l}\text { Rhodes et al., } \\
2020\end{array}$ & $\sqrt{ }$ & $\sqrt{ }$ & & $\sqrt{ }$ & $\sqrt{ }$ & & & \\
\hline $\begin{array}{l}\text { Sanchez et al., } \\
2020\end{array}$ & $\sqrt{ }$ & $\sqrt{ }$ & $\sqrt{ }$ & & $\sqrt{ }$ & $\sqrt{ }$ & $\sqrt{ }$ & \\
\hline $\begin{array}{l}\text { Santos et al., } \\
2020\end{array}$ & $\sqrt{ }$ & $\sqrt{ }$ & $\sqrt{ }$ & & $\sqrt{ }$ & & & $\sqrt{ }$ \\
\hline $\begin{array}{r}\text { Siewe Fodjo } \\
\text { et al., } 2020\end{array}$ & $\sqrt{ }$ & $\sqrt{ }$ & & & & & & \\
\hline $\begin{array}{l}\text { Stephenson } \\
\text { et al., } 2020\end{array}$ & $\sqrt{ }$ & & $\sqrt{ }$ & & & $\sqrt{ }$ & $\sqrt{ }$ & \\
\hline $\begin{array}{l}\text { Stephenson } \\
\text { et al., } 2020\end{array}$ & $\sqrt{ }$ & & $\sqrt{ }$ & & & $\sqrt{ }$ & $\sqrt{ }$ & \\
\hline
\end{tabular}

appointments cancelled by healthcare providers as a result of COVID-19 [26, 27]. Rao et al.'s [22] study across 20 countries also found that disruptions in HIV care were associated with COVID-19 containment measures, with one in five people unable to access their healthcare provider and $65.0 \%$ unable to access prescriptions remotely. Participants from upper middle-income countries, such as Mexico $(85.7 \% ; 60 / 70)$ and Russia $(86.5 \% ; 345 / 399)$, were more likely to experience difficulty accessing healthcare or prescriptions than their high-income counterparts [22].

Qualitative research provided some insight into reasons for disrupted HIV care, including two US studies where participants described difficulties accessing general medical care [25, 29]. Reflecting these concerns one participant responded: "I'm terrified that my needs and options will become harder to have due to the long-lasting time that I'm hearing that the coronavirus will be lasting, i.e. resources 
will be fewer and more difficult to find" [25]. Gwadz et al.'s [45] mixed method study of 96 African American and Latinx PLHIV in New York city, found that telemedicine had minimised difficulties accessing ART for around one in four participants (22.0\%), but others described it as inferior and more time consuming compared with in-person care.

\section{Stress and Mental Health}

The psychosocial impacts of stress accumulated across a life course increase the chances of poor mental health and premature death [46]. With the emergence of COVID-19, a number of editorials suggested many PLHIV were experiencing anxiety and stress linked to both concerns associated with contracting SARS-COV-2 and its impact on their HIV treatment [2, 14, 16, 43, 44, 47, 48]. Brown and Weissman [43] argued older PLHIV frequently have preexisting experiences of loneliness and poor mental health, while Chenneville et al. [2] raised concerns that PLHIV, who are already disproportionately at risk, may develop adverse mental health outcomes as a result of limited mobility and social isolation during the COVID-19 pandemic.

The impacts of COVID-19 on mental health, including increased experiences of stress, anxiety and depression were described in nearly half the primary research studies [19-21, 23-25, 29, 31, 45]. A survey of 16 older PLHIV in Miami, USA found participants reported increased stress associated with their sense of social isolation and fragile economic situation [24]. Elevated feelings of anxiety, associated with acquiring or transmitting COVID-19, or having a family member affected were also commonly reported [19-21, 29, 31]. Not surprisingly, participants who reported higher levels of anxiety and depression also reported losing their jobs during the pandemic [19]. Summarising the increasing sense of anxiety, one participant in a US based study by Krier et al. [25] described their concerns about: "everything being complicated with fear and anxiety associated with having my condition during the coronavirus period." (p2).

Jones et al. [21] compared the effects of social support on depressive symptoms in PLHIV in the USA and Argentina during COVID-19. Highlighting the critical buffering role social support can play, they found greater perceived social support was associated with lower depressive symptoms among PLHIV in Argentina, but not in the US [21]. They attributed the US results to the country's more individualist values, which may weaken the effects of social support [21].

\section{Food Insecurity}

Food security, and concerns associated with both economic and physical access to sufficient food [49] was discussed across both the editorials and primary research. Key editorials highlighted food insecurity and its potential association with other negative biomedical and psychosocial impacts including, non-adherence to ART, treatment interruptions and disruption to clinic visits $[50,51]$. Across the primary research, food insecurity was reported in six studies [19, 27, $28,31,32,36,45]$. Santos and colleagues [19] found $20.0 \%$ of PLHIV in a global cohort study had cut or skipped meals completely, while around $40.0 \%$ of PLHIV from two US based studies experienced difficulty accessing food during the year [27, 31]. A study of predominantly African American and Latinx PLHIV living in New York city found 84.0\% met the criteria for food insecurity and $48.0 \%$ of participants were not in stable housing [45]. Younger participants were most likely to report difficulties accessing food, which was potentially linked to higher rates of unemployment among those reliant on casual work [31]. Participants who had engaged in greater protective behaviours to mitigate risk of COVID-19 infection, such as avoiding or reducing social contact and physical distancing, also experienced difficulty accessing food [27]. Consequently, participants reported skipping meals during the ongoing pandemic or described challenges associated with buying food during the pandemic $[31,32,36]$. Poteat et al.'s [28] study, involving transgender women living with HIV in the US, found they were almost five times more likely to be food insecure than the general population.

\section{Social Isolation and Loneliness}

Social isolation, or the absence of social contact with peers, is a key social issue for many PLHIV, particularly older PLHIV, and may lead to loneliness and poor health outcomes $[14,43,52]$. With heightened uncertainty surrounding COVID-19, Marziali and colleagues [14] raised concerns that rates of social isolation and loneliness in PLHIV would continue to increase. Reinforcing this, a number of primary research studies identified social isolation and loneliness as key concerns for PLHIV [24, 26, 27, 29, 34]. Algarin and colleagues [24] found older PLHIV were already experiencing isolation but suggested this may have increased during the pandemic. The impact of social isolation was also present in younger PLHIV, with in-person social support adversely affected by the pandemic [29].

Protective behaviours to minimise risk associated with contracting COVID-19, as well as restrictions around gatherings and work-from-home protocols, resulted in reduced social interactions [26, 27]. As one participant in Rhodes et al.'s [29] study noted: "It is affecting my interactions with other people; I do not see my family and friends anymore." Others drew parallels between living through the COVID-19 pandemic and first learning of their HIV status: "I do feel alone, and it kind of reminds me of when I learned I had HIV" [29]. 


\section{Impacts to Employment, Income and Education}

The economic impacts of the COVID-19 pandemic are far reaching, as unemployment rates have risen globally. Some editorials focused on the economic impacts on PLHIV broadly; however, some groups including older, long term diagnosed PLHIV, were considered more susceptible to the financial impact of the pandemic [43].

Eight primary research articles explored the impact of COVID-19 on employment, income and education for PLHIV [19, 21, 28, 29, 31, 34, 35, 45]. Santos et al. [19] identified $11.0 \%$ of participants living with HIV had lost around $30.0 \%$ of their income due to COVID-19. Sanchez et al. [31] found participants in a US survey had experienced difficulty paying rent, a third had their work hours cut and nearly one in five had lost their jobs as a direct result of COVID-19 [31]. Decreased work hours were also reported by a third of participants in a study by Bogart et al. [35]. A New York based study conducted by Gwadz et al. [45] found only $8.0 \%$ of participants were employed and $43.0 \%$ had run out of funds for necessities, indicating extreme poverty. Men living with HIV in the US interviewed by Rhodes et al. [29] reported lost educational opportunities and described the financial impact of job losses as well as the loss of stable housing. Poteat et al. [28] found transgender women living with HIV were significantly more likely to be unemployed ( $76.6 \%$ vs. $45.2 \%, p<0.001)$, earn an income below the federal poverty level $(66.3 \%$ vs $38.7 \%, p<0.001)$, and were at heightened risk of violence in comparison to non-HIV-positive transgender women. Jones et al. [21] compared the impacts of COVID-19 on PLHIV in the US and Argentina and found PLHIV in Argentina exhibited better coping methods during the pandemic, which they attributed to people having learnt to adapt through the country's ongoing economic crisis [21].

\section{Impacts on Sexual Behaviour}

The impacts of COVID-19 on sexual behaviours among gay and bisexual men living with HIV was a minor theme, with editorials highlighting the impact of the pandemic and associated social restrictions on reducing the number of sexual partners [47, 53]. Alpalhão and Filipe [53] suggested this may have resulted in a reduction in sexually transmitted illness (STI) but may have also negatively impacted development of important sexual relationships.

Two research papers, that engaged a broad sample of MSM and included sub-samples of PLHIV, examined the impact of COVID-19 on sexual behaviour and reported changes in sexual behaviours, including avoiding close physical contact and reducing or ceasing sex with casual partners $[31,33]$. In contrast, Stephenson and colleagues $[32,36]$ found MSM in a US survey reported an increase in the number of sexual partners during the COVID-19 pandemic, but PLHIV were more likely to report a decrease in the number of sexual partners.

\section{Impacts on Substance Use}

Use of recreational drugs including methamphetamines is positively correlated with medication non-adherence [54]. This creates an increased risk of COVID-19 complications for PLHIV who may use recreational drugs. In their editorial, Peavy et al. [55] described setbacks to treatment for opioid use as a result of the pandemic, with clinics required to make major policy changes to ensure care was not impacted. In contrast, primary research investigating the impacts of COVID-19 on substance use behaviours including recreational drugs such as marijuana and methamphetamine, as well as alcohol and tobacco [30-32, 34, 36], found increased alcohol consumption and binge drinking in MSM including those living with HIV [31, 32, 36], and an $8.0 \%$ increase in recreational drug use [30].

\section{Racial and Social Inequality, Stigma and Discrimination}

Many inequalities related to poor health outcomes, stigma and discrimination have been magnified through COVID-19 and highlighted in editorials, particularly those penned in the US [2, 56-59]. Authors drew attention to African American PLHIV, who have been disproportionately affected by COVID-19 and are more likely to develop health complications, experience homelessness, unemployment, poverty and/or disadvantage associated with the costs of health care [2, 17, 42, 56-59]. The challenges faced by women living with HIV (WLHIV) were rarely explored within the primary research literature; however Closson et al.'s [60] editorial sought to draw attention to WLHIV's increased risk of domestic violence as a result of stay-at-home measures. Stigma was also a point of discussion across several editorials, particularly racially driven discrimination of PLHIV of East Asian appearance and descent [26, 61, 62]. Logie and colleagues [61, 62] argued for HIV stigma reduction strategies to address COVID-19 related stigma.

Although identified as an area of significant concern among editorials, only four primary research articles explored racial disparity [9, 19, 35, 45]. Meyerowitz et al. [9] systematically identified all PLHIV diagnosed with COVID19 at a large hospital in Massachusetts and found nearly $80.0 \%$ were Black or Hispanic/Latinx - a figure substantially higher than the $40.0 \%$ Black or Hispanic/Latinx PLHIV registered in the local HIV clinic. Santos and colleagues [19] found PLHIV from racial minority groups experienced higher rates of interruption to accessing ART. Bogart et al. [35] identified high rates of mistrust around health information, including vaccine and treatment hesitancy, while 
highlighting the importance of community engagement in improving COVID-19 outcomes. They argue this mistrust stems from centuries of systemic racism and oppression by government and parallels similar mistrust concerning HIV [35]. Scepticism of various sources of health information, notably that provided by government sources, was identified by Gwadz et al. [45] with one participant stating: "I'm very skeptical about the federal government, I really don't trust [them] especially when you're dealing with people of color anyway, their record is not that good."

Examining the impact of stigma identified during the COVID-19 pandemic, Berman et al. [26] found PLHIV reported experiencing an average of six HIV-related microaggressions (eg., online bullying and discrimination). The authors identified the heightened vulnerability of PLHIV from racial minorities to HIV related stigma and discussed a lack of research into the experiences of African American PLHIV in particular. They also found a relationship between experiencing HIV related stigma and projecting COVID-19 related stigma towards others [26]. This often manifested as xenophobic or discriminatory attitudes towards migrants or visitors from countries such as China [26]. Discriminatory attitudes were also positively associated with self-imposed protective behaviours such as social distancing [26].

\section{Discussion}

This review has taken advantage of a unique point in time to explore emerging research examining COVID-19 and HIV to understand of the social impacts of the pandemic on the lives of PLHIV. Approximately 417 research papers and editorials, examining the association between COVID-19 and HIV, were produced in the first twelve months of the pandemic. With the US experiencing the highest number of cases of COVID-19 anywhere in the world during this time [1, 63], it is not surprising the majority of publications originated there. Importantly, the biomedical and clinical impacts of COVID-19 were a key focus of the early literature, providing essential information to PLHIV about their susceptibility to COVID-19 complications [7-11].

Of the research exploring the social impact of the pandemic, the majority were rapid, cross-sectional surveys, engaging existing cohorts or convenience samples of PLHIV designed to gain data within the shortest timeframe. Only a limited number of qualitative studies emerged in the early phase of COVID-19, which is not unexpected due to the time and resources required to conduct this research and the challenges of engaging in social interaction at this time. Nonetheless, the absence of a robust body of qualitative evidence highlights the urgent need for investment in a richer understanding of the impact of the pandemic on PLHIV. Another key limitation of the available research is generalisability.
Many included small samples, and only twelve of 20 studies used a sample of participants entirely consisting of PLHIV. Six papers focused on MSM and included sub-samples of men living with HIV [19, 22, 31-33, 36]. Research exploring the unique impacts of the pandemic on WLHIV is notable by its absence, but as Clossen et al. [60] argue, it is urgently needed to identify ways to support the safety and wellbeing of WLHIV. Likewise, the experiences of diverse subpopulations of PLHIV, such as those from gender minorities, who may experience increased vulnerability to the impacts of COVID-19, were underrepresented across the literature.

Of the key social impacts identified by this review, all intersected and highlighted the potential for heightened risk from the COVID-19 pandemic if HIV care and treatment is disrupted. COVID-19 illuminated existing psychosocial aspects of living with HIV. Access to HIV care, and changes in the way care is provided, were frequently identified in the literature. Many acknowledge the move to telehealth as a necessary step, but it has the potential to leave some PLHIV worse off, particularly when technology cannot be accessed or if models of care are rigidly applied [26, 27, 40-42]. As Rhodes et al. [29] argue, HIV care providers are an important source of information and trust for PLHIV, and this relationship must be maintained. Disruption of this relationship serves to highlight the tenuous nature of the social support some PLHIV rely on and can further isolate vulnerable groups and magnify existing isolation and loneliness [29, $42,43]$. The negative impacts of social isolation may in turn have profound consequences for the health and wellbeing of PLHIV, particularly those who are older or already isolated. Similarly, unemployment and loss of income has resulted in some PLHIV sacrificing food to afford medication, with food insecurity a risk factor for lower HIV treatment adherence, low CD4 cell counts and incomplete HIV viral load suppression [50]. This recursive cycle of precarity serves to position PLHIV at heightened risk but also highlights the multiple points at which policy makers and service providers must act to redress the current impact of the pandemic on PLHIV.

Examining editorials through this review allowed us to determine whether research was aligned with calls to action from leaders in the field. Findings from the primary research generally mirrored issues and topics examined within editorials; however, the call for recognition and action on the inequalities amplified by COVID-19 was strongest by those contributing to editorial discussions. Many editorials explicitly considered the disparity in COVID-19 related outcomes for PLHIV among ethnic and racial minorities, but only four studies investigated this directly. African American and Latinx PLHIV in the US are showing disproportionate rates of COVID-19 infection and mortality, as well as increased levels of homelessness and unemployment [9, 35, 56, 57]. Furthermore, mistrust of government sources, notably the 
President and elected officials, has the potential to cause treatment and vaccine hesitancy in minority populations, paralleling the HIV epidemic [29, 35, 45]. That PLHIV across racial groups are experiencing such great disparity in COVID-19 incidence is cause for urgent investigation. Structural and social factors that disproportionately affect racial minorities must be addressed to mitigate this disparity [9]. Challenges with accessing healthcare, along with social and economic pressures associated with the pandemic may explain higher rates of infection [17, 56, 57], but also pinpoint opportunities for action and support. Primary research into COVID-19 related stigma was also lacking despite Logie et al.'s [61, 62] acknowledgement that stigma is one of the main causes of reduced access to healthcare. Maria Fusco et al. [64] argue stigma has resulted in a reluctance of PLHIV testing for COVID-19, resulting in many going undiagnosed. Migrants and racial minorities living with HIV may experience this burden of stigma disproportionately, particularly the intersections of multiple stigmas associated with racism, HIV status and COVID-19 [56, 65]. Given awareness of the impact of stigma and rising inequalities on PLHIV, the call now rests with the research community to investigate and build empirical understandings of these issues at this critical time.

This review provides important insight into emerging research examining experiences of two parallel pandemics; however, there are a number of limitations associated with the review process that must be acknowledged, most notably the focus on high income countries. Boundaries needed to be placed on the review, but given the global impact of COVID19 future investigation must understand the lived experiences of PLHIV in low- and middle-income countries. More broadly, the search strategy was developed as a wide filter to capture all research published in the first twelve months of the pandemic, nonetheless it is possible relevant studies were missed. Inclusion of more articles would have strengthened findings and may have introduced social impacts that are not present within the scope of this paper, although there is little doubt that as the pandemic continues the breadth of understanding will deepen and intensify.

\section{Conclusion}

Findings from this review highlight the need for more research into the social impacts of the COVID-19 pandemic on PLHIV. The many social consequences created or magnified by the pandemic are linked to disruptions in HIV care, which can lead to medication non-adherence, social isolation, poor mental health outcomes and increased substance use. Impacts on income and employment render treatment options less accessible, while also creating food insecurity. The importance of maintaining HIV care and outreach, particularly for those already vulnerable to disadvantage including older PLHIV, transgender women living with HIV and those of racial minorities are also critical early findings. Future research must be directed to address these outcomes for PLHIV and ensure health professionals, service providers and policy makers are equipped to respond to the negative impacts of COVID-19.

Author contributions Not applicable.

Funding Not applicable.

Data availability Not applicable.

Code availability Not applicable.

\section{Declarations}

Conflict of interest Not applicable.

Ethical approval Not applicable.

Consent to participate Not applicable.

Consent for publication Not applicable.

\section{References}

1. Johns Hopkins Corona Virus Resource Centre (JHCVRC). COVID Dashboard [internet], Baltimore, Maryland: John Hopkins University; 2020. [updated 2021 Mar 20; cited 2021 Mar 20]. Available from: https://coronavirus.jhu.edu/map.html.

2. Chenneville T, Gabbidon K, Hanson P, Holyfield C. The Impact of COVID-19 on HIV Treatment and Research: A Call to Action. Int J Environ Res Public Health. 2020;17(12):4758.

3. Bhaskaran K, Rentsch CT, MacKenna B, Schultze A, Mehrkar A, Bates CJ, et al. HIV infection and COVID-19 death: a population-based cohort analysis of UK primary care data and linked national death registrations within the OpenSAFELY platform. Lancet HIV. 2021;8(1):e24-e32.

4. Cooper TJ, Woodward BL, Alom S, Harky A. Coronavirus disease 2019 (COVID-19) outcomes in HIV/AIDS patients: a systematic review. HIV Med. 2020;21(9):567-77.

5. Gao Y, Chen Y, Liu M, Shi S, Tian J. Impacts of immunosuppression and immunodeficiency on COVID-19: a systematic review and meta-analysis. J Infect. 2020;81(2):e93-5.

6. Geretti AM, Stockdale AJ, Kelly SH, Cevik M, Collins S, Waters L, et al. Outcomes of COVID-19 related hospitalization among people with HIV in the ISARIC WHO Clinical Characterization Protocol (UK): a prospective observational study. Clin Infect Dis. 2020; ciaa1605.

7. Lesko CR, Bengtson AM. HIV and SARS-CoV-2: Intersecting Epidemics with Many Unknowns. Am J Epidemiol. 2021;190(1):10-16.

8. Mellor M, Bast A, Jones N, Roberts N, Ordonez-Mena J, Reith A, et al. Risk of adverse COVID-19 outcomes for people living with HIV: a rapid review and meta-analysis. medRxiv. 2021;35(4):F1-F10. 
9. Meyerowitz EA, Kim AY, Ard KL, Basgoz N, Chu JT, Hurtado RM, et al. Disproportionate burden of COVID-19 among racial minorities and those in congregate settings among a large cohort of people with HIV. Aids. 2020;34(12):1781-1787.

10. Center for Disease Control. What to Know About HIV and COVID-19 [internet]. Atlanta, Georgia: CDC; 2020 [updated 2020 July 28; cited 2020 Dec 14]. Available from: https://www. cdc.gov/coronavirus/2019-ncov/need-extra-precautions/hiv.html

11. Prabhu S, Poongulali S, Kumarasamy N. Impact of COVID-19 on people living with HIV: A review. J Virus Erad. 2020;6(4):100019.

12. van Bilsen WPH, Zimmermann HML, Boyd A, Davidovich U. Burden of living with HIV among men who have sex with men: a mixed-methods study. Lancet HIV. 2020;7(12):e835-43.

13. McDaid L, Flowers P. Pandemics have psychosocial and sociocultural burdens. Lancet HIV. 2020;7(12):e801-2.

14. Marziali ME, Card KG, McLinden T, Wang L, Trigg J, Hogg RS. Physical distancing in COVID-19 May exacerbate experiences of social isolation among people living with HIV. AIDS Behav. 2020;24(8):2250-2.

15. Ware NC, Wyatt MA, Tugenberg T. Social relationships, stigma and adherence to antiretroviral therapy for HIV/AIDS. AIDS Care. 2006;18(8):904-10.

16. Shiau S, Krause KD, Valera P, Swaminathan S, Halkitis PN. The burden of COVID-19 in people living with HIV: a syndemic perspective. AIDS Behav. 2020;24(8):2244-9.

17. Ridgway JP, Schmitt J, Friedman E, Taylor M, Devlin S, McNulty M, et al. HIV Care Continuum and COVID-19 Outcomes Among People Living with HIV During the COVID-19 Pandemic, Chicago, IL. AIDS Behav. 2020;24(10):2770-2772.

18. Braun V, Clarke V. Using thematic analysis in psychology. Qual Res Psychol. 2006;3(2):77-101.

19. Santos GM, Ackerman B, Rao A, Wallach S, Ayala G, Lamontage E, et al. Economic, mental health, HIV prevention and HIV treatment impacts of COVID-19 and the COVID-19 response on a global sample of cisgender gay men and other men who have sex with men. AIDS Behav. 2021;25(2):311-321.

20. Siewe Fodjo JN, Faria de Moura Villela E, Van Hees S, Tibério Dos Santos T, Vanholder P, Vanholder P, et al. Impact of the COVID-19 pandemic on the medical follow-up and psychosocial well-being of people living with HIV: a cross-sectional survey. J Acquir Immune Defic Syndr. 2020;85(3):257-262.

21. Jones DL, Ballivian J, Rodriguez VJ, Uribe C, Cecchini D, Salazar AS, et al. Mental health, coping, and social support among people living with HIV in the Americas: a comparative study between Argentina and the USA during the SARS-CoV-2 pandemic. AIDS Behav. 2021:1-9.

22. Rao A, Rucinski K, Jarrett B, Ackerman B, Wallach S, Marcus $\mathrm{J}$, et al. Perceived interruptions to HIV prevention and treatment services associated with COVID-19 for gay, bisexual, and other men who have sex with men in 20 countries. J Acquir Immune Defic Syndr. 2021;87(1):644-651.

23. Kuman TunÇel Ö, PullukÇu H, Erdem HA, Kurtaran B, TaŞbakan SE, TaŞbakan M. COVID-19 related anxiety in people living with HIV: an online cross-sectional study. Turk J Med Sci. 2020;50(8):1792-1800.

24. Algarin AB, Varas-Rodríguez E, Valdivia C, Fennie KP, Larkey L, $\mathrm{Hu} \mathrm{N}$, et al. Symptoms, stress, and HIV-related care among older people living with HIV during the COVID-19 pandemic, Miami, Florida. AIDS Behav. 2020;24(8):2236-8.

25. Krier S, Bozich C, Pompa R, Friedman MR. Assessing HIV-related stigma in healthcare settings in the era of the COVID-19 pandemic, Pittsburgh, Pennsylvania. AIDS Behav. 2020;24(9):2483-5.

26. Berman M, Eaton LA, Watson RJ, Andrepont JL, Kalichman S. Social Distancing to Mitigate COVID-19 Risks Is Associated
With COVID-19 Discriminatory Attitudes Among People Living with HIV. Ann Behav Med. 2020;54(10):728-737.

27. Kalichman SC, Eaton LA, Berman M, Kalichman MO, Katner $\mathrm{H}$, Sam SS, et al. Intersecting pandemics: impact of SARSCoV-2 (COVID-19) protective behaviors on people living with HIV, Atlanta. Georgia J Acquir Immune Defic Syndr. 2020;85(1):66-72.

28. Poteat TC, Reisner SL, Miller M, Wirtz AL. COVID-19 Vulnerability of Transgender Women With and Without HIV Infection in the Eastern and Southern U.S. Acquir Immune Defic Syndr. 2020;85(4):e67-e69.

29. Rhodes SD, Mann-Jackson L, Alonzo J, Garcia M, Tanner AE, Smart BD, et al. A rapid qualitative assessment of the impact of the COVID-19 pandemic on a racially/ethnically diverse sample of gay, bisexual, and other men who have sex with men living with HIV in the US South. AIDS Behav. 2021;25(1):58-67.

30. Hochstatter KR, Akhtar WZ, Dietz S, Pe-Romashko K, Gustafson $\mathrm{DH}$, Shah DV, et al. Potential influences of the COVID-19 pandemic on drug use and HIV care among people living with HIV and substance use disorders: experience from a pilot mHealth intervention. AIDS Behav. 2021;25(2):354-9.

31. Sanchez TH, Zlotorzynska M, Rai M, Baral SD. Characterizing the impact of COVID-19 on Men who have sex with men across the United States in April, 2020. AIDS Behav. 2020;24(7):2024-32.

32. Stephenson R, Chavanduka TMD, Rosso MT, Sullivan SP, Pitter RA, Hunter AS, et al. Sex in the time of COVID-19: results of an online survey of gay, bisexual and other men who have sex with men's experience of sex and HIV prevention during the US COVID-19 epidemic. AIDS Behav. 2021;25(1):40-8.

33. Hammoud MA, Maher L, Holt M, Degenhardt L, Jin J, Murphy $\mathrm{D}$, et al. Physical distancing due to COVID-19 disrupts sexual behaviours among gay and bisexual men in Australia: implications for trends in HIV and other sexually transmissible infections. J Acquir Immune Defic Syndr. 2020;85(3):309-315.

34. Cooley SA, Nelson B, Doyle J, Rosenow A, Ances BM. Collateral damage: impact of SARS-CoV-2 pandemic in people living with HIV. Journal of NeuroVirology. 2021;27(1):168-170.

35. Bogart LM, Ojikutu BO, Tyagi K, Klein DJ, Mutchler MG, Dong L, et al. COVID-19 Related medical mistrust, health impacts, and potential vaccine hesitancy among black americans living With HIV. J Acquir Immune Defic Synd. 2021;86(2):200-7.

36. Stephenson R, Chavanduka TMD, Rosso MT, Sullivan SP, Pitter RA, Hunter AS, et al. Contrasting the perceived severity of COVID-19 and HIV Infection in an online survey of gay, bisexual, and other men who have sex with men during the U.S. COVID-19 epidemic. Am J Mens Health. 2020;14(5):1557988320957545.

37. Rogers BG, Arnold T, Schierberl Scherr A, Strong SH, Holcomb $\mathrm{R}$, Daley Ndoye C, et al. Adapting substance use treatment for HIV affected communities during COVID-19: comparisons between a sexually transmitted infections (STI) clinic and a local community based organization. AIDS Behav. 2020;24(11):2999-3002.

38. Rogers BG, Coats CS, Adams E, Murphy M, Stewart C, Arnold T, et al. Development of telemedicine infrastructure at an LGBTQ+ clinic to support HIV prevention and care in response to COVID19, Providence, RI. AIDS Behav. 2020;24(10):2743-7.

39. Rebeiro PF, Duda SN, Wools-Kaloustian KK, Nash D, Althoff KN. Implications of COVID-19 for HIV Research: data sources, indicators and longitudinal analyses. J Int AIDS Soc. 2020;23(10):e25627.

40. Dandachi D, Freytag J, Giordano TP, Dang BN. It is time to include telehealth in our measure of patient retention in HIV care. AIDS Behav. 2020;24(9):2463-5.

41. Mgbako O, Miller EH, Santoro AF, Remien RH, Shalev N, Olender S, et al. COVID-19, telemedicine, and patient empowerment in HIV care and research. AIDS Behav. 2020;24(7):1990-3. 
42. Beima-Sofie K, Ortblad KF, Swanson F, Graham SM, Stekler JD, Simoni JM. "Keep It Going if You Can": HIV service provision for priority populations during the COVID-19 pandemic in Seattle, WA. AIDS Behav. 2020;24(10):2760-63.

43. Brown MJ, Weissman SB. The impact of COVID-19 on older adults living with HIV: HIV care and psychosocial effects. J Gerontol Soc Work. 2020;63(6-7):602-6.

44. Operario D, King EJ, Gamarel KE. Prioritizing community partners and community HIV workers in the COVID-19 pandemic. AIDS Behav. 2020;24(10):2748-50.

45. Gwadz M, Campos S, Freeman R, Cleland CM, Wilton L, Sherpa D, et al. Black and Latino persons living with HIV evidence risk and resilience in the context of COVID-19: a mixedmethods study of the early phase of the pandemic. AIDS Behav. 2021;25(5):1340-60.

46. Wilkinson R, Marmot M. Social determinants of health - the solid facts. In: Social determinants of health - the solid facts. World Health Organization; 2003.

47. Ballester-Arnal R, Gil-Llario MD. The virus that changed Spain: impact of COVID-19 on people with HIV. AIDS Behav. 2020;24(8):2253-7.

48. Shoptaw S, Goodman-Meza D, Landovitz RJ. Collective call to action for HIV/AIDS community-based collaborative science in the era of COVID-19. AIDS Behav. 2020;24(7):2013-6.

49. Food and Agriculture Organisation of the United Nations (FAO). FAO in the 21st century: ensuring food security in a changing world [internet]. Rome, Italy: Food and Agriculture Organisation; 2011. Available from: http://www.fao.org/3/i2307e/i2307e.pdf.

50. McLinden T, Stover S, Hogg RS. HIV and food insecurity: a syndemic amid the COVID-19 pandemic. AIDS Behav. 2020;24(10):2766-69.

51. Weiser SD, Young SL, Cohen CR, Kushel MB, Tsai AC, Tien PC, et al. Conceptual framework for understanding the bidirectional links between food insecurity and HIV/AIDS. Am J Clin Nutr. 2011;94(6):1729s-s1739.

52. Pantell M, Rehkopf D, Jutte D, Syme SL, Balmes J, Adler N. Social isolation: a predictor of mortality comparable to traditional clinical risk factors. Am J Public Health. 2013;103(11):2056-62.

53. Alpalhão M, Filipe P. The impacts of isolation measures against SARS-CoV-2 infection on sexual health. AIDS Behav. 2020;24(8):2258-9.

54. Colfax G, Shoptaw S. The methamphetamine epidemic: implications for HIV prevention and treatment. Curr HIV/AIDS Rep. 2005;2(4):194-9.
55. Peavy KM, Darnton J, Grekin P, Russo M, Green CJB, Merrill $\mathrm{JO}$, et al. Rapid implementation of service delivery changes to mitigate COVID-19 and maintain access to methadone among persons with and at high-risk for HIV in an opioid treatment program. AIDS Behav. 2020;24(9):2469-72.

56. Nydegger LA, Hill MJ. Examining COVID-19 and HIV: the impact of intersectional stigma on short- and long-term health outcomes among African Americans. Int Soc Work. 2020;63(5):655-9.

57. Millett GA, Honermann B, Jones A, Lankiewicz E, Sherwood J, Blumenthal S, et al. White Counties Stand Apart: The Primacy of Residential Segregation in COVID-19 and HIV diagnoses. AIDS Patient Care STDS. 2020;34(10):417-424.

58. Arnold C. Covid-19: How the lessons of HIV can help end the pandemic. BMJ. 2021;372:n216.

59. Millett GA. New pathogen, same disparities: why COVID-19 and HIV remain prevalent in U.S. communities of colour and implications for ending the HIV epidemic. J Int AIDS Soc. 2020;23(11):e25639.

60. Closson K, Lee M, Gibbs A, Kaida A. When home is not a safe place: impacts of social distancing directives on women living with HIV. AIDS Behav. 2020;24(11):3017-9.

61. Logie CH. Lessons learned from HIV can inform our approach to COVID-19 stigma. J Int AIDS Soc. 2020;23(5):e25504.

62. Logie CH, Turan JM. How do we balance tensions between COVID-19 public health responses and stigma mitigation? learning from HIV research. AIDS Behav. 2020;24(7):2003-6.

63. Center for Disease Control. CDC COVID Data tracker [internet]. Atlanta, Georgia: CDC; 2020 [updated 2021 Mar 20; cited 2021 Mar 20]. Available from: https://covid.cdc.gov/covid-data-track er/\#cases_casesper100klast7days.

64. Maria Fusco F, Sangiovanni V, Tiberio C, Papa N, Atripaldi L, Esposito V, et al. Persons living with HIV may be reluctant to access to COVID-19 testing services: data from 'D. Cotugno' Hospital, Naples, Southern Italy. AIDS. 2020;34(14):2151-52.

65. Waterfield KC, Shah GH, Etheredge GD, Ikhile O. Consequences of COVID-19 crisis for persons with HIV: the impact of social determinants of health. BMC Public Health. 2021;21(1):299.

Publisher's Note Springer Nature remains neutral with regard to jurisdictional claims in published maps and institutional affiliations. 